\title{
SAVREMENI PROBLEMI DOMAĆEG I INOSTRANOG TURIZMA U JUGOSLAVIJI
}

\author{
Stevan M.Stankovic*
}

IZVLEČEK

UDK 911.3:796.5 (497.1)

Turizam u Jugoslaviji ima dugu i bogatu tradiciju. Domaci turizam ima nekoliko osnovnih karakteristika. Analiza je pokazala da su neke od njih identične sa stranim turizmom. To znaci da obe vrste turizma treba sinhronizovano razvijati.

ABSTRACT

CONTEMPORARY PROBLEMS OF DOMESTIC AND FOREIGN TOURISM IN YUGOSLAVIA

Tourism in Yugoslavia has a long and rich tradition. Domestic tourism in Yugoslavia has several basic characteristics. The analysis has shown that some of them are identical with foreign tourism. This means that both kinds make a unique whole.

\section{UVOD}

Domaci i inostrani turizam u Jugoslaviji ima dugu tradiciju, koja je od značaja i za savremeno stanjc. Od najranijih poðetaka, razvoj turizma na tlu naše zemlje, pratile su odgovarajuce druStvene i profesionalne organizacije. Neke od njih bile su i ostale osnova sadašn jih društvenih i profesionalnih institucija iz domena turizma, ugostiteljstva, zastite prirode za potrebe turizma, inicijative i receptive turistixkog prometa. Savremeni turizam u Jugoslaviji se odlikuje uðeక̌em velikog broja naših gradjana i stranaca u razlixitim vrstama turistickih kretanja. Turizam je tokom vremena uslovio niz novih pojava i procesa u prostoru, koje ranije nisu biie ni dovoljno poznate ni dovoljno istražene. Kako su domaci $i$ inostrani turizam od znacaja za platni bilans zemlje, zapošljavanje, preusmeravanje potrošnje, invetiaanje u odgovarajuce smeštajne, ugostiteljske, saobracajne kapacitete i objekte komunalne infrastrukture, turizam se nameçe kao polifunkcionalna delatnost u v:cmenu i prostoru, sa nizom specifiěnih zahteva, koji se moraju rešavati na osnovu detaljnih naučnih istraživanja stru$\varepsilon_{n}$ jaka razlicitih profila, pri $\chi^{2}$ enu geografi imaju jasno definisano mesto (Stankovic, 1987, 42).

* Dr., univ.prof., Geografski fakultet, PMF, 11000 Beograd, Studentski trg 3/III. 
Domaci turisticki promet predstavlja prelivanje dela lixne potrošnje iz brojnih matixnih u sve brojnija turistixka mesta i ima veliki ekonomski znacaj. Osnovni pravci kretanja našeg stanovništva su usmereni iz kontinentalnog ka primorskom prostoru, iz velikih gradova $\mathrm{i}$ industrijskih centara ka izleltistima, planinama $\mathrm{i}$ banjama, kao i iz regije gusce naseljenosti ka regijama koje su bogate spomenixkim vrednostima i dobro oxuvanom prirodom. Domaci turizam se mora uvažavati i sa zdravstvenog, vaspitnog, kulturnog i socijalnog znacaja. Na ovim njegovim osobinama poxivaju vanekonomske funkcije, koje je potrebno vise i sistematicnije negovati i unapredjivati, jer je turizam osnova patriotizma, druželjublja i medjusobnog zbližavanja ljudi udal jenih prostora.

Domaci turizam u Jugoslaviji se u periodu posle drugog svetskog rata udvijao u razlicitim drustvenim i ckonomskim uslovima, te je imao i razlicita obeležja, ali u celini gledano znacajan uzlazni trend. Sedamdesetih godina turizam dobija status prioriteta, te se grade brojni objekti, unapredjuje propaganda i uvode stimulativne mere na nivou federacije. Već tada jasno se ispoljila čnjenica da je veća pažnja posvecivana inostranom nego domacem turizmu, te se poxinju nazirati izvesne disproporcije. Najvise objekata izgradjeno je u priobalju Jadranskog mora i na ostrvima, te je jos jąe naglašena usmerenost turista iz kontinentalnih prostora ka primorskim. To je izazvalo i povećanu koncentraciju turistixkog prometa na letnje mesece, kada su uslovi za rekreativni boravak najpoveljniji. Kako je u medjuvremenu sve jasnije ispoljen pad vrednosti dinara prema konvertibilnim valutama, došlo je do povecanja cena turistickih roba i usluga. Visoka lǐ̌na i turisticka potrošnja u mnogim stranim zemljama iz kojih Jugoslavija dobija najviše turiste (SR Nemacka, Austrija, İtalija, Velika Britanija) uz pad kupovnc noći domaceg stanovništva, uslovili su nove proporcije u ukupnom turističkom prom:tu. Više i bolje planiran je i programiran razvoj inostranog nego domaceg turizma u Jugoslaviji. To proistice iz zna‘aja deviznog priliva po osnovu turizma za pobolišanje platnog bilansa zemlje, koji je godinama negativan. U trci za devizama, dinar kao sredstvo placenja je zapostavljen. Činjenica je da turizam nikada nije bio uzrok inflaciji i devalvaciji dinar, ali je delio sudbinu sliěnih uslužnih delatnosti i zajedno sa saobracajem ublaživao deficit platnog bilansa (Stankovic, 1983, 201).

\section{DEVIZNI PRIHOD}

Godine 1988. naša zemlja je ostvarila ukupan devizni prihod od 22,9 milijardi dolara. Od toga je 12,8 milijardi dolara dobijeno izvozom razlixitih roba, a 11,1 milijarda dolara zaradjena turizmom, saobracajnim uslugama, prijemom doznaka nasih gradjana iz inostranstva i iz drugih izvora. Sa 2,024 milijarde dolara prihoda od stranih turista, 
turizam je u ukupnom deviznom prihodu nase zemlje uxestvovao sa $8,83 \%$, a u nerobnom prilivu deviza sa $18,23 \%$. Bez obzira sto je inostrani turizam u Jugoslaviji zncajan izvor deviznih prihoda, stanje se mora posmatrati u kontekstu niza okolnosti. Naime, devizni priliv po osnovu razvoja inostranog turizma u našoj zemlji 1987. godine u odnosu na prihode ostvarene 1986. godine, povecao se oko $15 \%$. U isto vreme dinar je prema dolaru devalvirao za $400 \%$. Namece se jasan zakljucak, da su nosioci razvoja turizma u Jugoslaviji, za nešto više ostvarenih deviza, morali dati znatno viß̌e roba i pružiti znatno viß̌e usluga. Takvo stanje direktno i indirektno utiče na ubrzanje inflacije, a ova negativno na domaci turizam (Stankovic, 1989, 53).

Devizni prihodi od inostranog turizma u dolarima

$\begin{array}{lccc}\text { Godina } & \text { Prihod } & \text { Godina } & \text { Prihod } \\ 1955 . & 7.200 .000 & 1975 & 768.414 .000 \\ 1960 . & 15.882 .000 & 1980 & 1.114 .700 .000 \\ 1965 . & 81.700 .000 & 1985 & 1.050 .200 .000 \\ 1970 & 274.200 .000 & 1988 . & 2.024 .000 .000\end{array}$

Promene pariteta dinara prema konvertibilnim sredstvima placanja, uslovljavaju snižavanje cena roba i turistiðkih usluga za strane turiste. Zbog toga se naša zemlja mogla konkurentno ukljuxivati u osvajanje stranog turistiðkog tržišta. Viß̌struko je potvrdjeno, da je to najlosiji nacin osvajanja tržista, jer borba za isto mora bazirati na odstranjivanju nelojalne konkurencije unutar našc ponude, promociji novih turistiðkih vrednosti, svrsishodnijoj propagandi, obogacivanju sadržaja boravka, produženju sezone, veçoj vanpansionskoj potrošnji i slǐnno. "Uz relativnu stabilnost dinara, naroxito u razdoblju od 1974. do 1977. godine, jos smo se i mogli uljuljkivati u uvjerenju da je gubljenje pozicija na svjetskom turistiðkom tržistu rezultat cinjenice sto je Jugoslavije izgubila prednost koju je u ranijim godinama imala po osnovi cijena turistiðkog usluga. Medjutim, neuspješno nastojanje Jugoslavije da se uglavnom porastom smjestajnih kapaciteta i sporim mijenjanjem okoštale strukture ponude održi na svjetskom tržištu nižim cijenama svojih usluga, najbolje se ogleda u raskoraku izmedju porasta prometa i deviznog priliva po osnovi inozemnog turizma. Ali, kada vise iz platno-bilansnih razloga nije bila u mogucnosti da osigura niti ravnomjernu opskrbljenost tržista osnovnim prehrambenim i drugim robama, Jugoslavija je u 1982. godini zabilježila veliki pad i prometa i potrošnje stranih turista. Naime, upravo je neoðekivano nagli porast salda dohotka od turizma u razdoblju od 1960. do 1973. godine, unatoð visestrukih zastoja u posljednjih petnaestak godina i drastǐnog pada u 1982. godini, doprineo tome da se izvozne mogucnosti jugoslavenskog turizma kao i njegov doprinos platnoj bilanci zemlje cesto preuvelicavaju" (Vučković, 1987, 180). 
Savremeni problemi...

\section{TURISTIČNI PROMET}

U razvoju domaceg $i$ inostranog turizma u našoj zemlji ima dosta razlika, ali su ispoIjene i izvesne zajednicke osobenosti. Medju njima se istiðu sve veca mobilnost turista, naglašen sezonski karakter, neravnomerno povečanje prometa po godinama, izrazita usmerenost ka Jadranskom moru i ostrvima, prošrenje promena na veci broj turistixkih mesta, kao i moguénost izdvajanja karakterističnih perioda. Zajednicke odlike ukazuju na potrebu jedinstvenog pracenja $i$ usmeravanja razvoja obe vrste prometa.

$\begin{array}{lccc}\text { Godina } & \text { Domaci } & \text { Strani } & \text { D. S. } \\ 1948 . & 1.616 .756 & 61.500 & 96: 4 \\ 1950 . & 2.319 .697 & 41.221 & 98: 2 \\ 1955 . & 2.925 .768 & 485.294 & 86: 14 \\ 1960 . & 4.314 .903 & 873.140 & 83: 17 \\ 1965 . & 5.284 .000 & 2.658 .000 & 66: 34 \\ 1970 . & 7.112 .000 & 4.748 .000 & 60: 40 \\ 1975 . & 9.711 .000 & 5.835 .000 & 62: 38 \\ 1980 . & 11.679 .100 & 6.410 .400 & 64: 36 \\ 1985 . & 13.579 .000 & 8.436 .000 & 62: 38 \\ 1987 & 13.349 .000 & 8.907 .000 & 60: 40\end{array}$

Sl.1. Domaći i strani turisti u Jugoslaviji

Porast broja domacih turista u Jugoslaviji po pojedinim godinama i dužim vremenskim periodima, dosta je neravnomeran, što je uslovljeno delovan jem niza faktora u mestima stalnog boravka stanovnistva, kao i umestima njihovog turistickog opredeljenja. Promet domacih turista zavisio je i zavisi od odgovarajucih pozitivnih i negativnih promena u privredi, politici i drustvenoj stvarnosti. Uz to, na obim promcta dcluju stimulativne mere, navike, potrebe i mogucnosti za promenom mesta boravka. Inostrani turizam u našoj zemlji pokazuje bržc stope rasta. Tome je doprinelo nekoliko jednokratnih devaivacija dinara, otvorenost granica naSe zemlje, prepoznativost Jugoslavije na inostranom turistixkom tržištu, povoljan geografski poiožaj, reiativno dobra saobracajna povezanost, velika vrednost prirodnih $\mathrm{i}$ antropogenih potencijala, sve obimnija materijalna baza, afirmacija nekih centara planinskog turizma i sl. Smatramo da je nepotrebno fiksirati odredjenc proporcije broja domacih i stranih turista. Na sadašnjem nivou razvoja turizma jecino opravdanje ima sinhronizovan razvoj obe vrste turistickog prometa. Mere nadležnih drržavnih $\mathrm{i}$ društvenih organizacija potrebno je jasno definisati, jer je celovit turistiðki promet osnova potpunijeg korišcenja postojecih turistickih vrednosti Jugoslavije koje su lokalnog, regionainog, republickog, jugoslovenskog, cvropskog i svetskog znacaja. Ukupnim razvojem turizma potrebno je uticati i na intenzivniji razvoj kontinentainih turistickih centara i regija, 
posebno banjskih, jezerskih i planinskih. Uz to, plasmanom ponude za kongresni, lovni i manifestacioni turizam, moguce je izvesno produženje turističke sezone, kao osnove za ostvarivanje vecih dinarskih i deviznih ekonomskih efekata (Stankovic, 1987, 43).

Broj nocenja domacih i stranih turista u Jugoslaviji pouzdaniji je pokazatelj turistiłog prometa, u odnosu na broj turista, te ga s pravom uvažavamo.

$\begin{array}{lrrr}\text { Godina } & \text { Domaci } & \text { Strani } & \text { D. S. } \\ 1948 . & 8.993 .638 & 417.907 & 96: 4 \\ 1950 . & 8.640 .158 & 178.541 & 98: 2 \\ 1955 . & 9.253 .974 & 1.832 .555 & 83: 17 \\ 1960 . & 19.512 .496 & 3.510 .500 & 85: 15 \\ 1965 . & 21.411 .000 & 11.240 .000 & 66: 34 \\ 1970 . & 25.943 .000 & 22.560 .000 & 53: 47 \\ 1975 . & 38.805 .000 & 31.622 .000 & 55: 45 \\ 1980 . & 50.128 .100 & 36.977 .900 & 57: 43 \\ 1985 . & 58.322 .100 & 50.816 .000 & 54: 46 \\ 1937 . & 57.684 .000 & 52.299 .000 & 52: 48\end{array}$

Sl. 2. Nocenja domacih i stranih turista u Jugoslaviji

Usporeniji rast broja nocenja domacih turista u odnosu na strane u Jugoslaviji, uslovila jc izrazita komercijalizacija turizma. "Razdoblje nakon privredne reforme (1965) karakteristixno je za domaci turizam u Jugoslaviji po tome sto on više nije potican državnim (drušstvenim) mjerama, vcć je prepušten prctežno tržištu i djelomieno krizi racinin kolektiva za odmor svojih clanova. Praktixno, umjesto dotadašnjeg gledanja na đomaci turizam kao socijalnu kategoriju, prelazi se na tretman turizma kao ekononske katcgorije koju opredeljuje kupovna moc i razina osobne potroß̌nje (tada joక̌ niske). Kako nisu bili ustvoreni uvjeti za takav razvitak domaceg turizma, a neposredno nakon reforme ti su uvjeti pogorకani u odnosu na ranije razdoblje (povecanje cijena i ukidanje povlastica" (Kobašc, 1987, 14). Komplementarnot izmedju domaceg $\mathrm{i}$ inostranog turistiðkog prometa u našoj zem!ji jasno je utvrdjena. Utvrdjeno je da se pri svakom smanjenju inostranog turistiðkog prometa, povecava domaci. Najvece razlike evidentiraju se u hotelskom smestaju turista. Kada strani tưristi duže i više borave u hotelima, smanjuje se udeo domaceg prometa. Kada strani turisti ne pokazuju veče interesovanje za hotelskim smestajem, isti se nudi domacem turistickom tržištu, koje je u gotovo citavom posleratnom razvoju turizma, a naročito u vreme njegove komerciajalizacije posle sedamdesetih godina, svojevrsna rezerva turistixke ponude (KobaKić, 1987, 18). 

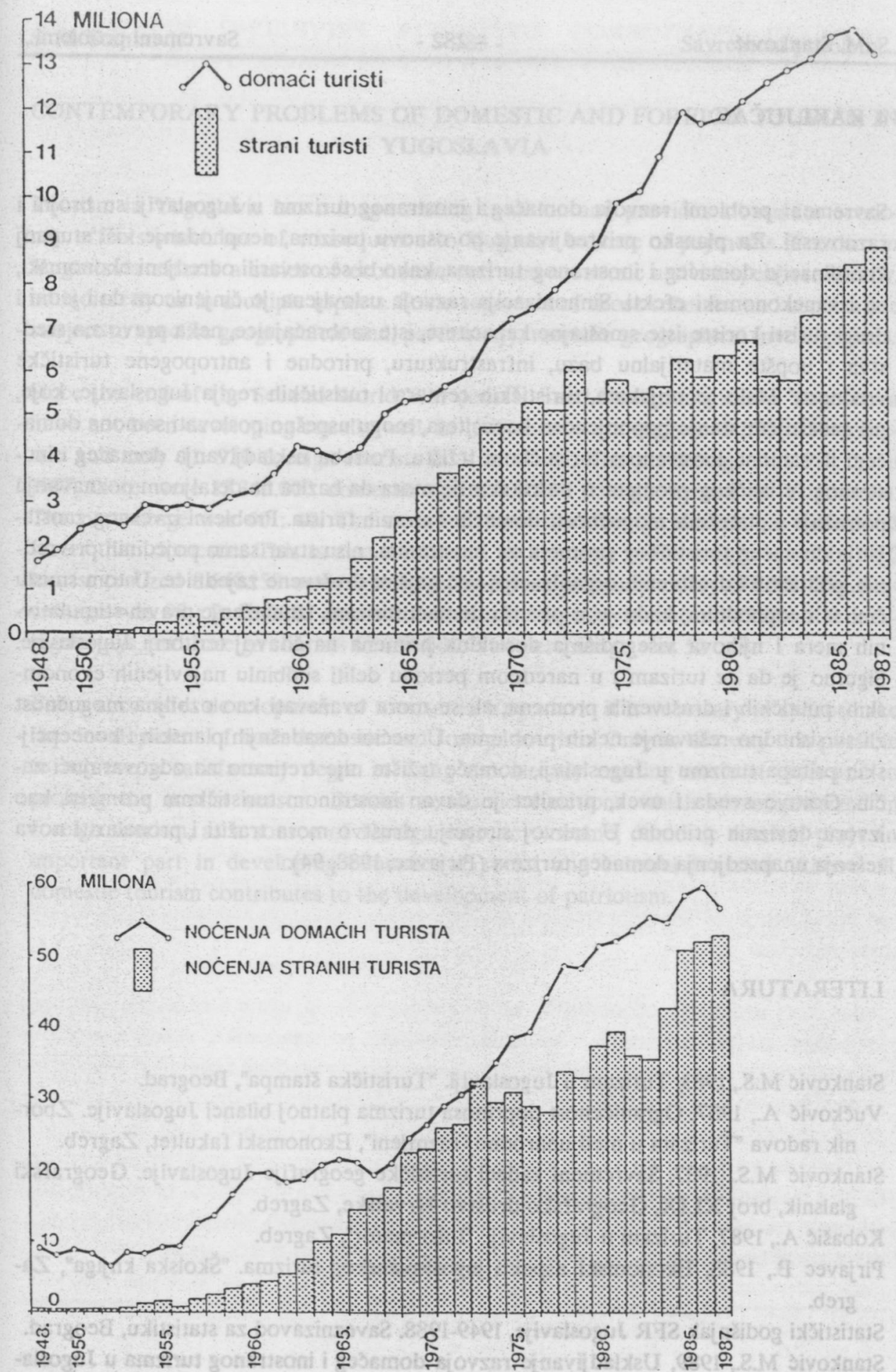

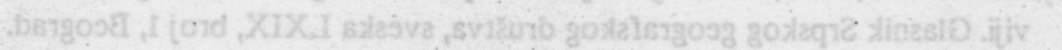




\section{ZAKLJUČAK}

Savremeni problemi razvoja domaceg i inostranog turizma u Jugoslaviji su brojni i raznovrsni. Za plansko privredjivanje po osnovu turizma, neophodanje visi stupanj koordinacije domaceg i inostranog turizma, kako bi se ostvarili odredjeni ekonomski, ali i vanekonomski efekti. Sinhonizacija razvoja uslovljena je cinjenicom da i jedni i drugi turisti koriste iste smestajne kapacitete, iste saobracajnice, neka prevozna sredstva $\mathrm{i}$ uopste materijalnu bazu, infrastrukturu, prirodne $\mathrm{j}$ antropogene turisti ke vrednosti. Malo je objekata, turistickih centara i turistickih regija Jugoslavije, koje, pri sadašnjem stanju poponjenosti kapaciteta, mogu uspešno poslovati samona domacem ili samona inostranom turistickom tržistu. Potreba uskladjivanja domaceg i inostranog turistiðkog prometa u našj zemlji, mora da bazira na detaljnom poznavanju potražnje i platežnih mogucnosti domacih i stranih turista. Probiemi izvesnog zaostajanja domaceg turistickog prometa za inostranim, nisu stvar samo pojedinih privrednih, politickih i društvenih organizacija, vec najšre društvene zajednice. U tom smislu čni se neophodnim, kada je u pitanju comaći turizam, iznalaženjc pravih stimulativnih mera i njihova viß̌godisnja dosicldna primena na Citavoj teritoriji Jugoslavije. Sigurno je da ce turizam i u narednom periodu deliti sudbinlu najavljenih ekonomskih, politixkih i društvenih promena, ali se mora uvažavati kao ozbiljna moguénost za svrsishodno rešavanje nekih problema. $U$ većini dosadašnjih planskih i koncepcijskih pritupa turizmu u Jugoslaivji, domace tržiste nije tretirano na odgovarajuci na-

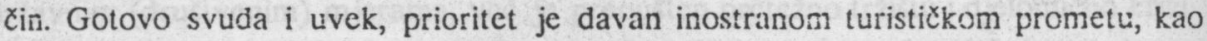
izvoru deviznih prihoda. U takvoj situaciju društvo mora tražiti i pronalaziti nova rešnja unapredjenja domakeg turizma (Pir javec, 1988, 94).

\section{LITERATURA}

Stankovič M.S., 1983, Turizam u Jugoslaviji. "Turistička Štampa", Beograd.

Vuckkovic A., 1987, Ogranǐ̌enost doprinosa turizma platnoj bilanci Jugoslavijc. Zbornik radova "Turizam u medjunarodnoj razmjeni", Ekonomski fakultet, Zagreb.

Stankovic M.S., 19S7, Savrcmeni zadaci turistiðke geografije Jugoslavije. Geografski glalsnik, broj XLIX, Geografsko društvo Hrvatske, Zagreb.

Kobaši A., 1987, Turizam u Jugoslaviji. "Informator", Zagreb.

Pir javec R., 198S, Ekonomski aspckti jugoslovanskog turizma. "Školska knjiga", Zagreb.

Statistixki godišnjak SFR Jugoslavije, 1949-1988. Saveznizavod za statistiku, Beograd.

Stankovic M.S., 1989, Uskladjivanje razvoja domaceg i inostranog turizma u Jugoslaviji. Glasnik Srpskog geografskog društva, sveska LXiX, broj 1, Beograd. 


\section{CONTEMPORARY PROBLEMS OF DOMESTIC AND FOREIGN TOURISM IN YUGOSLAVIA}

Tourism in Yugoslavia has a long-standing tradition and provides a basis for economic effects which are of consequence to Yugoslav balance of payments. Tourism in Yugoslavia affects a series of economic and non-economic activities, either directly, or indirectly or in multiple aspects. Some segments of those relations and aspects are subject to specific geographical and, particularly, touristic geographical investigations.

Since the end of the Second World War domestic and foreign tourism in Yugoslavia have not been developing equally well. In 1949 there were registered 1.985 .630 domestic and only 31.920 foreign tourists in Yugoslavia. The percentage was $98: 2$. In 1987 there were 13.349 .000 domestic and 8.907 .000 foreign tourists in Yugoslavia. The percentage was $60: 40$. The statistics shows that foreign tourism has developed faster than domestic. This is also confirmed by the data on overnight stays. In 1950 tourist realized 8.640 .158 overnight stays, and foreign tourists only 178.541 . The percentage was $98: 2$. In 1987 domestic tourists in Yugoslavia realized 57.684 .000 overnight stays, and foreign tourists 52.299 .000 . The percentage was $52: 48$.

For a successful development of tourism in Yugosiavia it is necessary to synchronize the development of both domestic and foreign tourism. Only in this way it is possible to achieve a satisfactory degre in using the already existing material basis and to prolong the tourist season. Besides economic functions which are emphasized in foreign tourism, as a source of foreign currency income, domestic tourism plays an important part in developing educational, social, and cultural function. Above all, domestic tourism contributes to the development of patriotism. 